\title{
THE FUNCTION OF THE HEART IN ENDOMYOCARDIAL FIBROSIS OF THE RIGHT VENTRICLE
}

\author{
BY \\ E. H. O. PARRY* AND D. GORDON ABRAHAMS $\dagger$ \\ From the Department of Medicine, University College Hospital, Ibadan, Nigeria, West Africa
}

Received January 7, 1963

Endomyocardial fibrosis is a common heart disease among the indigenous peoples of many of the tropical African countries. The morbid anatomical findings have been described in detail by Davies and Ball (1955) so that only the fundamental features require comment here. The initial lesion seems to be in the endocardium at the apex of either or both ventricles. Thence the fibrotic process spreads up the ventricular wall and the cavity of the ventricle is slowly obliterated from below. At the same time the papillary muscles become anchored in the bed of fibrous tissue: later the chordæ tendineæ and finally even the cusps of the atrio-ventricular valves are enmeshed as the fibrosis progresses, so that valvular incompetence results (Fig. 1). The fibrotic endocardium becomes rigid so that diastolic filling of the ventricle is restricted and the deformed atrioventricular valve allows blood to regurgitate. The inevitable changes in the function of the heart are more dramatic, and are easier to study, on the low pressure right side of the heart.

The clinical features of established right ventricular endomyocardial fibrosis have been described elsewhere by one of us (Abrahams, 1962), when some preliminary observations on cardiac output both at rest and after effort were reported. We report here the results of more detailed hæmodynamic studies of these deformed hearts and we have also compared our findings with published reports of patients with impaired diastolic filling of the ventricle from other causes.

\section{SubJECTS AND Methods}

In all, more than 30 patients with right ventricular endomyocardial fibrosis were studied. The left ventricle may also have been diseased in some patients for reasons discussed below, but such disease was neither clinically evident, nor functionally important. In several patients the clinical diagnosis was subsequently confirmed at necropsy.

Cardiac catheterization was carried out by the usual technique with the patient supine after fasting for at least six hours. Pressures were measured with an Elema-Schonander three-channel direct-writing recorder and capacitance electromanometer. The reference point for all measurements was $5 \mathrm{~cm}$. below the sternal angle in the mid-axillary line, which was assumed to be the centre of the right atrium. (In those patients with aneurysmal dilatation of the right atrium such an assumption may not be correct, but we know of no better reference point.) The cardiac output was determined by the direct Fick formula. All the patients had ascites, sometimes of large volume: for this reason we have not expressed the cardiac output in terms of cardiac index, but have preferred to retain the actual figures. Blood oxygen saturations were measured with a hæmoreflector (Kipp and Son, Delft) which was calibrated against the Van Slyke manometric apparatus. The oxygen saturation of every blood sample was invariably measured in duplicate: if these results differed, the mean of four readings on the hæmoreflector was taken. Frequently the right ventricle could not be

\footnotetext{
* Present address: Department of Medicine, Postgraduate Medical School, Hammersmith W.12.
}

$\uparrow$ Present address: Department of Cardiology, Prince Henry Hospital, Sydney, N.S.W., Australia. 


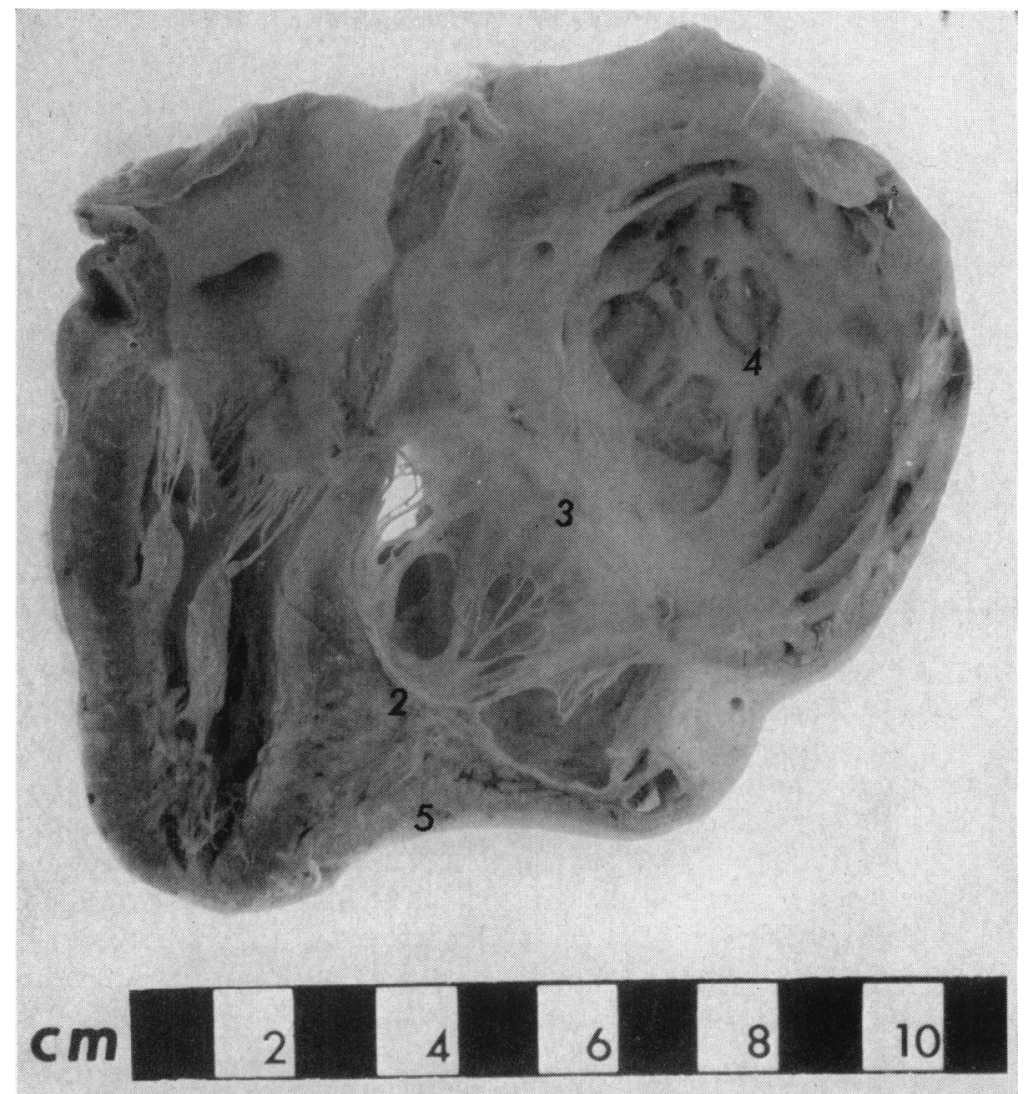

Fig. 1.-Advanced endomyocardial fibrosis of the right ventricle. The heart of a 12-year-old boy cut vertically and viewed from behind showing - (1) the normal left ventricle; (2) the obliterated apex of the cavity of the right ventricle, with fibrous tissue involving the papillary muscles; $(3)$ the dilated tricuspid valve ring; (4) the aneurysmal right atrium; (5) indrawing of the epicardium due to fibrotic shrinkage in the endocardium of the right ventricle.

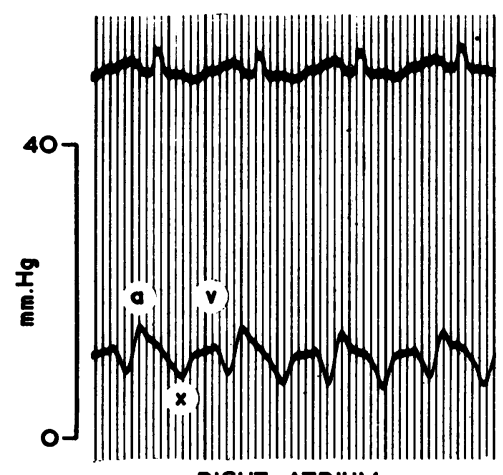

RIGHT ATRIUM

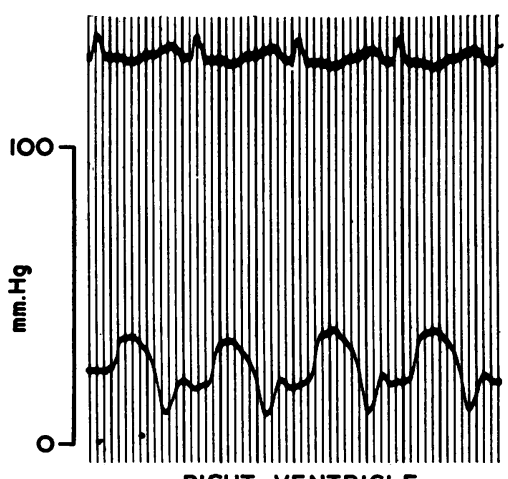

RIGHT VENTRICLE

Fig. 2.-Pulses from the right atrium and right ventricle in early endomyocardial fibrosis. These were taken from a 28-year-old woman with early endomyocardial fibrosis of the right ventricle. The atrial tracing shows a high mean pressure with an " $m$ " type of pulse wave, comprising " $a$ " and " $v$ " waves with " $x$ " and " $y$ " descents. The right ventricular pulse shows an early diastolic dip, which does not reach zero, a high diastolic plateau, and an attenuated systolic peak. 
catheterized because the right atrium and tricuspid valve were so deformed; and when this was so, a midatrial sample was used for estimation of mixed venous oxygen saturation. Arterial samples were obtained from an indwelling arterial needle of the Cournand type. Blood oxygen capacity was calculated from the hæmoglobin content of a blood sample removed during catheterization and so the data for oxygen capacity are derived. Oxygen consumption was measured with a Benedict-Roth spirometer filled with commercial oxygen. A freshly prepared $\mathrm{CO}_{2}$ absorber was always used, and we have no reason to think that any $\mathrm{CO}_{2}$ accumulated, which could further stimulate respiration.

Some patients exercised by kicking their legs in bicycle fashion against manual resistance. This was kept up for two to three minutes-the limit of comfortable endurance for most patients. When the cardiac output was measured on effort, the patient breathed from the spirometer throughout the period of effort. This method has been successfully used by others (Barratt-Boyes and Wood, 1957) without the data for spirometric oxygen consumption being found unreliable, and we have assumed that our data are similarly valid, particularly as our patients did only moderate exercise without excessive increases of tidal volume.

The slope of the oxygen consumption on the spirometer drum was not found to change appreciably after the first minute in our patients, and so the mean of the slope during the second and subsequent minutes was taken as the oxygen consumption. Arterial and mixed venous blood samples were taken during the third minute of exercise, or immediately at the end of the second minute if the patient could do no more. It was assumed that the "steady state" had been achieved by this time. Donald, Bishop, and Wade (1954) studied patients with rheumatic mitral valvular disease and found that in all but the very disabled the steady state was reached after two minutes, as judged by a constant arteriovenous oxygen difference.

For the Valsalva manœuvre, the patients blew the mercury column of a sphygmomanometer up to $40 \mathrm{~mm}$. and held it there for at least ten seconds.

When digoxin was given, the dose was $1 \mathrm{mg}$. diluted in $20 \mathrm{ml}$. of physiological saline and injected slowly over a period of one minute.

\section{RESULTS}

1. Pressure Curves from the Heart Chambers. It is convenient to discuss the right ventricular and right atrial pressure tracings together for they are interdependent. The characteristic ventricular pulse tracing is of the "dip-and-plateau" or "square-root" form owing to impaired diastolic filling of the ventricle. In patients with early lesions the rigid endocardium cannot relax properly and so this pulse occurs. This is reflected in the raised atrial filling pressure and the crisp " $a$ " wave in the right atrial tracing (Fig. 2). In more advanced disease when there is tricuspid regurgitation, the " $x$ " descent disappears from the atrial tracing which is now dominated by the systolic wave, and is very similar to the pulse tracing from the ventricle (Fig. 3).

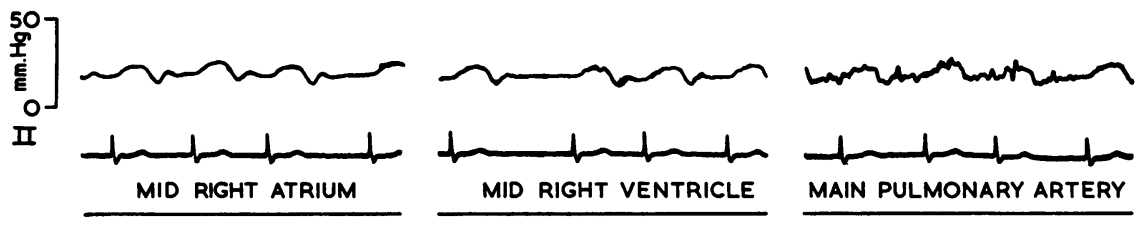

FIG. 3.-Pulse tracings from right atrium, right ventricle, and pulmonary trunk in advanced endomyocardial fibrosis. These tracings show that the end-diastolic right ventricular plateau pressure is often higher than the diastolic pressure in the pulmonary trunk. The slow rise in the pulmonary arterial pressure towards the end of diastole is clear in two of the cycles shown in this tracing.

We have analysed the components of the ventricular pressure tracings in 15 patients and these are presented in Table I. It will be seen that several patients had mild right ventricular hypertension, and we attribute this to coexistent left ventricular endomyocardial fibrosis, although this lesion was clinically silent. The level of the diastolic plateau - which is the pressure against which the atrium has to work in order to fill the ventricle-should also be noted. In the last column in Table I this plateau pressure has been expressed as a percentage of the ventricular systolic pressure; the figure is usually 50 per cent and sometimes higher. The implications of this will be discussed later. 
TABLE I

Right Ventricular Pressures (mm. $\mathrm{Hg}$ )

\begin{tabular}{|c|c|c|c|c|c|}
\hline \multirow[t]{2}{*}{ Case No.* } & \multirow{2}{*}{$\begin{array}{l}\text { Systolic } \\
\text { peak }\end{array}$} & \multicolumn{2}{|c|}{ Diastolic } & \multirow[t]{2}{*}{ Mean } & \multirow{2}{*}{$\begin{array}{c}\text { Plateau/systolic ratio } \\
\text { (per cent) }\end{array}$} \\
\hline & & dip & plateau & & \\
\hline $\begin{array}{r}6 \\
4 \\
27 \\
13 \\
17 \\
8 \\
25 \\
26 \\
28 \\
30 \\
21 \\
29 \\
31 \\
33 \\
5\end{array}$ & $\begin{array}{l}20 \\
40 \\
65 \\
48 \\
42 \\
21 \\
60 \\
35 \\
30 \\
40 \\
24 \\
33 \\
52 \\
60 \\
22\end{array}$ & $\begin{array}{r}2 \\
0 \\
10 \\
12 \\
13 \\
5 \\
6 \\
12 \\
3 \\
8 \\
4 \\
8 \\
0 \\
14 \\
8\end{array}$ & $\begin{array}{r}12 \\
17 \\
30 \\
20 \\
23 \\
15 \\
16 \\
25 \\
8 \\
20 \\
12 \\
16 \\
10 \\
35 \\
13\end{array}$ & $\begin{array}{l}\overline{25} \\
40 \\
23 \\
30 \\
\overline{32} \\
27 \\
15 \\
25 \\
16 \\
-27 \\
40 \\
-\end{array}$ & $\begin{array}{l}60 \\
42 \\
46 \\
42 \\
55 \\
74 \\
27 \\
71 \\
27 \\
50 \\
50 \\
50 \\
18 \\
58 \\
59\end{array}$ \\
\hline
\end{tabular}

* These numbers refer to a larger series.

2. Response of the Heart to Effort (11 patients). The results of these studies are given in Table II and in Fig. 4. Moderate leg exercise always caused a rise in heart rate, but in some patients, this rise was insignificant, probably because the resting heart rate was already rapid and so little increase could be expected. Other patients could not co-operate and it was impossible to exercise them adequately (Case 26, Table II).

Again, the oxygen consumption at rest was commonly raised above the accepted normal value, probably because our illiterate patients (who cannot speak English) do not understand what they should do when using a spirometer; in such patients fear and excitement cause higher oxygen consumptions.

In general it will be seen from Table II that the resting cardiac output tended to be low, but in some patients surprisingly high values were obtained, which were probably the result of the high values for oxygen consumption. All our patients had anæmia (the average $\mathrm{Hb}$. value was $11 \cdot 1 \mathrm{~g}$.) which in some was moderately severe, and this too may have tended to raise the cardiac output at rest.

TABLE II

The Effect of Effort on the Cardiac Output and Stroke Volume

\begin{tabular}{|c|c|c|c|c|c|c|c|c|c|c|c|c|c|c|}
\hline \multirow[t]{2}{*}{$\begin{array}{l}\text { Case } \\
\text { No. }\end{array}$} & \multirow[t]{2}{*}{$\begin{array}{c}\text { Age } \\
\text { (years) }\end{array}$} & \multirow[t]{2}{*}{ Sex } & \multicolumn{2}{|c|}{$\begin{array}{l}\text { Heart rate } \\
\text { /min. }\end{array}$} & \multicolumn{2}{|c|}{$\begin{array}{l}\text { Oxygen } \\
\text { consumption } \\
(\mathrm{ml} . / \mathrm{min} .)\end{array}$} & \multicolumn{2}{|c|}{$\begin{array}{l}\text { Arteriovenous } \\
\mathrm{O}_{2} \text { difference } \\
\text { (vol. } \% \text { ) }\end{array}$} & \multicolumn{2}{|c|}{$\begin{array}{l}\text { Cardiac } \\
\text { output } \\
\text { (1./min.) }\end{array}$} & \multicolumn{2}{|c|}{$\begin{array}{c}\text { Stroke } \\
\text { volume } \\
(\mathrm{ml} .)\end{array}$} & \multirow{2}{*}{$\begin{array}{c}\text { Arterial } \\
\text { oxygen } \\
\text { saturation } \\
\text { (rest) }\end{array}$} & \multirow[t]{2}{*}{$\underset{(\mathrm{g} . / 100 \mathrm{ml} .)}{\text { Hæmoglobin }}$} \\
\hline & & & Rest & Effort & Rest & Effort & Rest & Effort & Rest & Effort & Rest & Effort & & \\
\hline $\begin{array}{r}4 \\
8 \\
10 \\
17 \\
18 \\
21 \\
23 \\
25 \\
26 \\
27 \\
28\end{array}$ & $\begin{array}{l}15 \\
15 \\
32 \\
15 \\
40 \\
20 \\
25 \\
27 \\
30 \\
27 \\
42\end{array}$ & $\begin{array}{l}\mathbf{M} \\
\mathbf{M} \\
\mathbf{F} \\
\mathbf{M} \\
\mathbf{F} \\
\mathbf{F} \\
\mathbf{F} \\
\mathbf{F} \\
\mathbf{M} \\
\mathbf{F} \\
\mathbf{M}\end{array}$ & $\begin{array}{r}120 \\
96 \\
70 \\
120 \\
100 \\
120 \\
100 \\
92 \\
80 \\
98 \\
80\end{array}$ & $\begin{array}{r}140 \\
140 \\
110 \\
150 \\
120 \\
135 \\
120 \\
105 \\
84 \\
120 \\
100\end{array}$ & $\begin{array}{l}180 \\
210 \\
200 \\
200 \\
250 \\
275 \\
200 \\
280 \\
350 \\
250 \\
350\end{array}$ & $\begin{array}{l}250 \\
350 \\
360 \\
420 \\
400 \\
550 \\
450 \\
500 \\
450 \\
366 \\
750\end{array}$ & $\begin{array}{r}4 \cdot 5 \\
7 \cdot 4 \\
5.0 \\
5 \cdot 3 \\
6 \cdot 6 \\
5 \cdot 1 \\
6 \cdot 9 \\
5 \cdot 0 \\
5 \cdot 7 \\
10 \cdot 7 \\
5 \cdot 6\end{array}$ & $\begin{array}{r}6.0 \\
7.7 \\
6.1 \\
7.6 \\
8.6 \\
8 \cdot 5 \\
8 \cdot 1 \\
7.4 \\
6.6 \\
11.3 \\
5.9\end{array}$ & $\begin{array}{l}4 \cdot 1 \\
2 \cdot 7 \\
4 \cdot 0 \\
3 \cdot 7 \\
3 \cdot 7 \\
5 \cdot 4 \\
2 \cdot 9 \\
5 \cdot 6 \\
6 \cdot 1 \\
2 \cdot 3 \\
6 \cdot 3\end{array}$ & $\begin{array}{r}4 \cdot 2 \\
4.5 \\
6.0 \\
5 \cdot 5 \\
4 \cdot 5 \\
7 \cdot 5 \\
5 \cdot 5 \\
6 \cdot 8 \\
6 \cdot 8 \\
3.2 \\
12.6\end{array}$ & $\begin{array}{l}34 \\
28 \\
57 \\
30 \\
37 \\
45 \\
29 \\
61 \\
76 \\
24 \\
78\end{array}$ & $\begin{array}{r}32 \\
32 \\
54 \\
36 \\
39 \\
48 \\
46 \\
62 \\
81 \\
27 \\
126\end{array}$ & $\begin{array}{l}86 \\
88 \cdot 5 \\
92 \\
93 \cdot 5 \\
93 \\
95 \\
90 \\
92 \\
93 \\
99 \\
96\end{array}$ & $\begin{array}{r}10.6 \\
13.8 \\
11.6 \\
9.8 \\
10.5 \\
10.2 \\
11.6 \\
10.6 \\
9.8 \\
12.6 \\
11 \cdot 1\end{array}$ \\
\hline
\end{tabular}



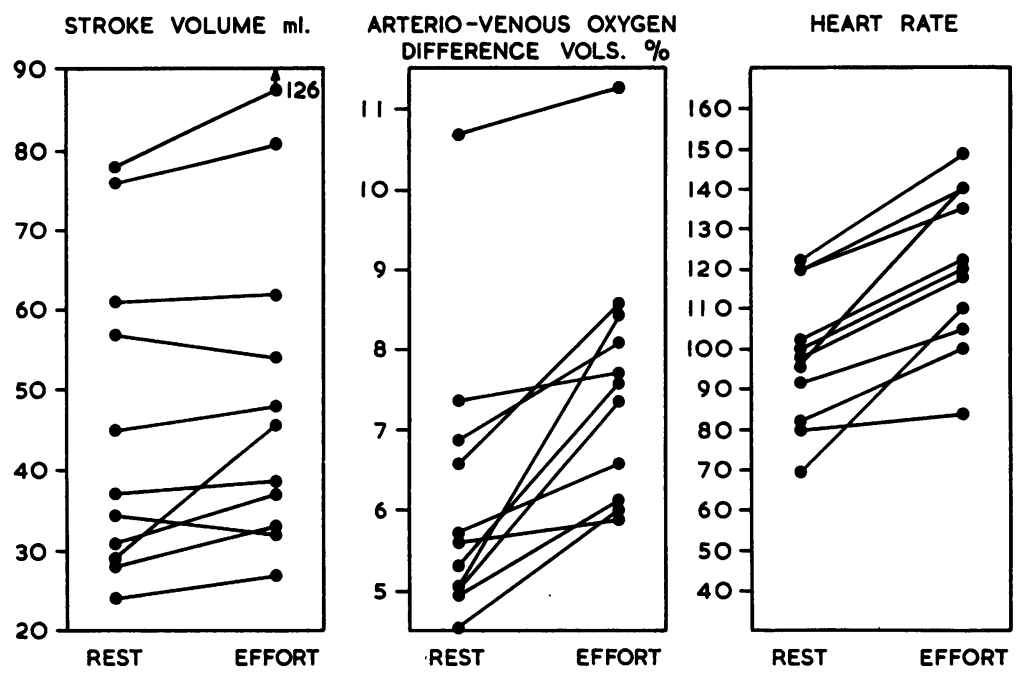

Fig. 4.-The effect of effort on stroke volume, arteriovenous oxygen difference, and heart rate. The virtually fixed stroke volume and the moderate increases in arteriovenous oxygen difference and in heart rate on effort are shown; the low absolute stroke volume in a number of patients is clear.

Exercise always provoked a rise in cardiac output, but for reasons discussed below this should be interpreted with caution.

We have also calculated the stroke-volume which, as might be expected, is low in most of the patients and, more significantly, it is virtually fixed and changes little on effort (Fig. 4). In two patients (Cases 23 and 28) the large change in stroke-volume on effort can only have been due to technical errors.

The arteriovenous oxygen difference does not seem great at rest, but this is due in part to the anæmia, and in part to the decreased arterial oxygen saturation. Because these factors are important, the oxygen extraction at rest is obviously greater than normal which accounts for the relatively small increase in extraction on effort (Fig. 4).

Oxygen desaturation of arterial blood occurred in most of the patients, but it was not found to increase on effort, and no manœuvre was done under the conditions of these studies, which could affect it significantly.

The mechanism of this phenomenon, which has been discussed elsewhere (Abrahams and Parry, 1963), is not directly related to the present study, but it may well depend upon a shunt of venous blood through the azygos system to the pulmonary veins, thus bypassing the right heart. If such a shunt exists - and the issue is by no means yet determined-there will clearly be a discrepancy between the individual outputs of the right and left ventricles, and the respective stroke volumes of these chambers will be similarly affected. Assuming the end-pulmonary capillary oxygen saturation to be 100 per cent, and using the Fick formula, the right ventricular stroke volume will obviously be significantly lower than that of the left ventricle. However, since we do not know whether such a shunt exists, we have ignored the possibility in the present paper, and have regarded the stroke volumes and outputs of both ventricles as identical.

In seven patients the mean right atrial pressure was measured before and after exercise. There was always a rise in right atrial pressure with exertion, though this varied in degree and in the time required for the pressure to return to pre-exercise levels (Fig. 5). Abrahams (1962) reported that there was usually a fall in right atrial pressure with exercise, but this statement demands revision in the light of further experience. 


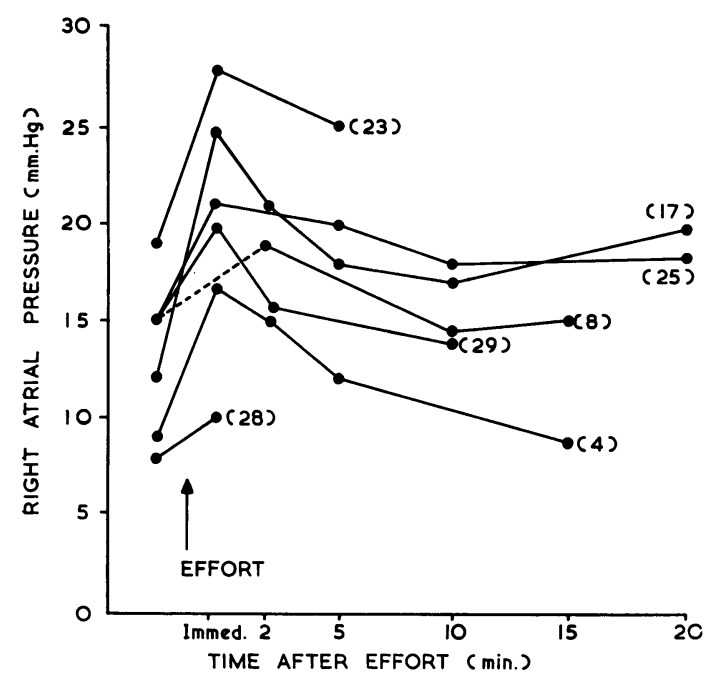

Frg. 5.-The effect of effort on the right atrial pressure. The sharp rise of the mean right atrial pressure after effort and its slow return to the resting level are clearly shown. The figures in brackets refer to the number of each patient in the entire series.

3. Other Studies on Right Atrial Pressure. (a) Intravenous Digoxin (6 patients). Digoxin had no effect either on the mean right atrial pressure or on the height of the various components of the atrial pressure tracing.

(b) Respiration. This was studied in those patients who could co-operate. The right atrial pressure always rose with inspiration and fell with expiration (Fig. 6). This response did not necessarily depend upon the presence of tricuspid regurgitation.

(c) Posture. As might be expected, the right atrial pressure fell when the patient was tilted from the horizontal towards the vertical position. This fall was sometimes considerable: in one subject the mean right atrial pressure fell from 17 to $11 \mathrm{~mm}$. $\mathrm{Hg}$ with this movement.

4. Studies on the Peripheral Arterial Pulse. (a) The Valsalva Mancuvre (7 patients). In all patients there was a "square-wave" response with no subsequent "over-shoot" (Fig. 7). This response did not appear in any way to depend upon the size of the heart: in two patients the heart was scarcely enlarged, whereas in two others it was very large owing to an aneurysmal right atrium. In another patient a chronic pericardial effusion was present.

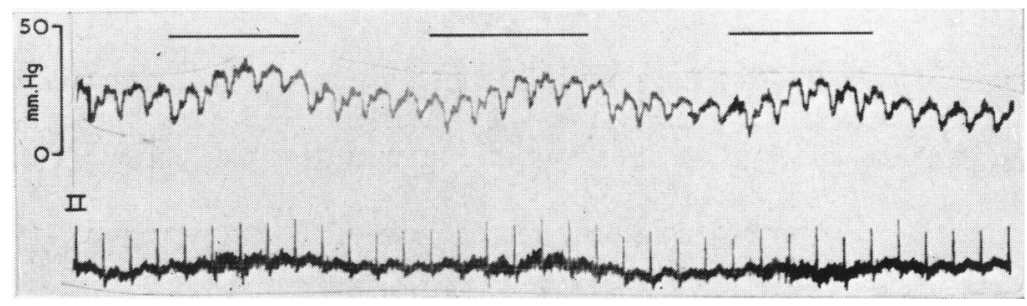

FIG. 6.-The effect of respiration on the right atrial pulse (inspiration synchronous with the continuous line). The rise of right atrial pressure on inspiration and its fall on expiration are clearly shown. This tracing was taken from a man with advanced endomyocardial fibrosis of the right ventricle and tricuspid regurgitation.

(b) The Effect of Respiration. The effect of exaggerated respiration was to produce "pulsus paradoxus" and, again, this response did not appear to be related to the size of the heart, nor to the presence of pericardial effusion. In one patient with a huge right atrium, and in whom subsequent necropsy revealed virtual obliteration of the right ventricular cavity, the radial pulse became almost imperceptible on inspiration (Fig. 8). It must be pointed out, however, that this patient had atrial fibrillation.

\section{Discussion}

We do not propose to discuss the characteristics of the right atrial pressure curve in any detail here, since they are closely linked to the natural history of endomyocardial fibrosis which is to be 


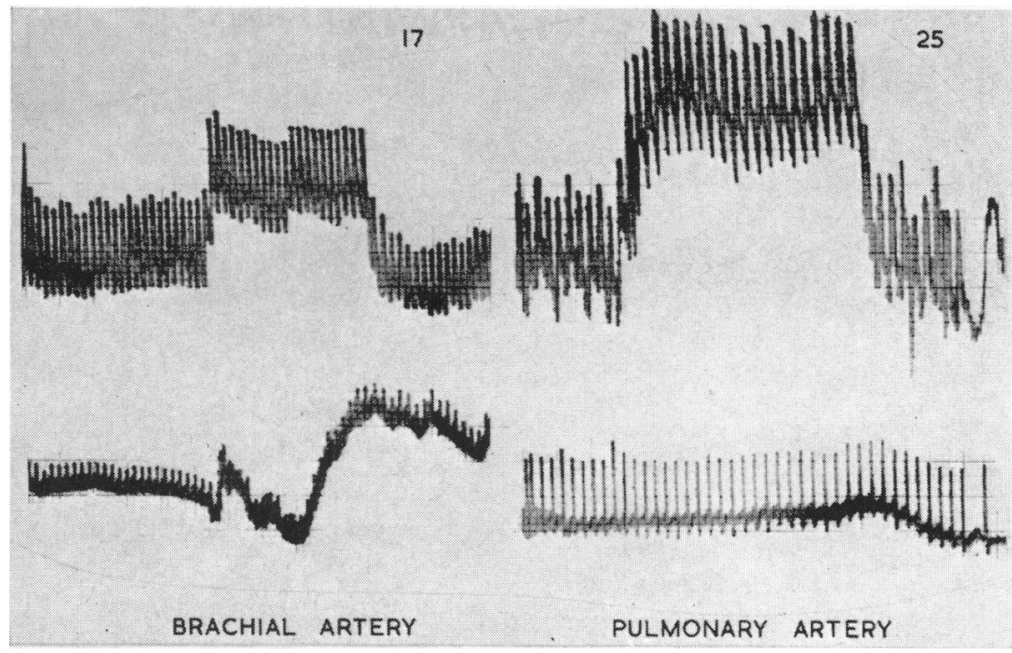

FIG. 7.-The Valsalva manœuvre. A square-wave response from the pulmonary artery and from the brachial artery in two different patients with endomyocardial fibrosis, associated with a small and a large heart, respectively.

presented in detail elsewhere, but the "dip-and-plateau" form of the ventricular pressure tracing does demand some comment. This pulse was first reported by Bloomfield et al. (1946), from Cournand's laboratory, in patients who had either right ventricular failure with tricuspid regurgitation, or constrictive pericarditis. Hansen, Eskildsen, and Götzsche (1951) confirmed its presence in constrictive pericarditis, and $\mathrm{Yu}$ et al. (1953) suggested that the diastolic plateau/systolic peak ratio, if more than one-third, was valuable in the diagnosis of constrictive pericarditis, where this was in doubt clinically. The consistently high values for this ratio in our patients demand that this statement be modified to include patients with endocardial as well as pericardial constriction. The "dip-and-plateau" pulse is a constant finding in endocardial fibrosis (Clark, Valentine, and Blount, 1956; Alajouanine et al., 1959; Gerbaux et al., 1956; Gerbaux, Garin, and Lenègre, 1957; Abrahams, 1960; Shillingford and Somers, 1961): indeed Gerbaux and Rullière (1958) emphasized this pattern of "endocardial constriction," a term originally employed by McKusick and Cochran (1952). Intrinsic disease of the heart muscle from any cause may be accompanied by impaired diastolic filling, and the "dip-and-plateau" right ventricular pulse has been reported in amyloidosis (Hetzel,

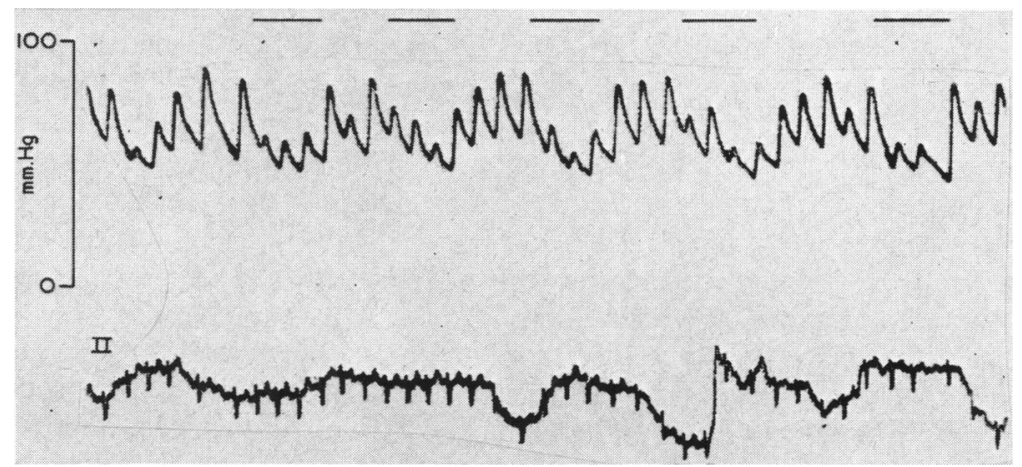

FIG. 8.-The effect of respiration on the peripheral arterial pulse (inspiration synchronous with the continuous line). The very small pulse pressure on inspiration is remarkable. 

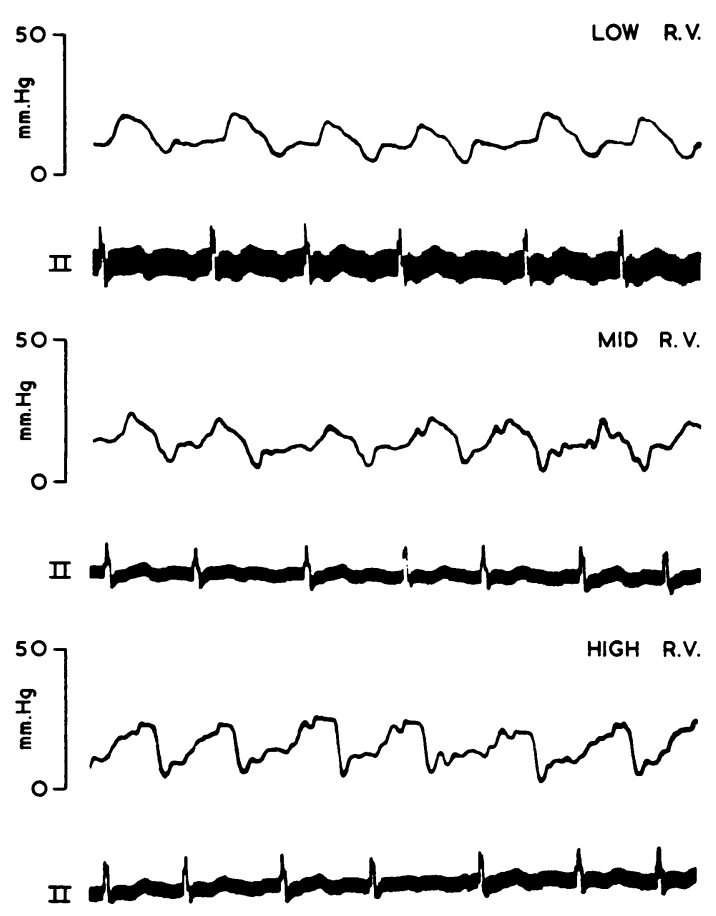

FIG. 9.-Pulse tracings from three sites in the right ventricle in advanced endomyocardial fibrosis. The subject is a 21-year-old woman. The upstroke time is progressively longer from low to high sites; low R.V. $0.08 \mathrm{sec}$, mid R.V. 0.20 sec., high R.V. 0.24 sec.
Wood, and Burchell, 1953; Gunnar et al., 1955), in diffuse myocardial fibrosis (Burwell and Robin, 1954), and in cardiomyopathy (Goodwin et al., 1961). Evidently the pattern is non-specific, and is of little use for diagnostic purposes.

Other features of the right ventricular pressure pulse are the blunted appearance of the systolic wave (Fig. 3 and 9), and the prolonged upstroke time, which may be as long as $0 \cdot 24$ sec., and may vary in different sites in the same ventricular cavity (Fig. 9): this we attribute to partial obliteration of the ventricular cavity, resulting in stenosis of the outflow tract. As the disease advances, ventricular contraction is impaired as well as its relaxation, and this is shown in a fall in the systolic pressure and in the prolonged upstroke time. Finally, the diastolic dipwhich in early cases may be negative-is positive even at its nadir, indicating that the ventricle cannot empty satisfactorily: this is further evidence that the ventricle cannot contract forcibly enough against the rigid and resisting endocardium.

In the normal person the greater demand for oxygen provoked by exercise is met by increasing the oxygen extraction from the blood and by raising the cardiac output.
important factor. The oxygen extraction in Initially the enhanced oxygen extraction is the more important factor. The oxygen extraction in
our patients is already high at rest, possibly because they are already compensating to some extent. Also, the oxygen-carrying power of the arterial blood is impaired by anæmia, and the arterial blood is frequently desaturated, so that there can be relatively little increase in the arteriovenous oxygen difference with exercise, and the increased demand for oxygen is met by a rise in heart rate and/or an increase in stroke volume. In endomyocardial fibrosis, where the right ventricle is rigid and attenuated, little rise in stroke-volume is to be expected, and any increase in cardiac output must be due to the increase in heart-rate. In general this is borne out by our results.

It is in this context that the amount of exercise done by our patients is important. Donald et al. (1955) studied this problem and divided their subjects according to oxygen consumption into those who did light, intermediate, high, and very high work. They found that normal subjects in the light exercise group doubled their oxygen consumption, nearly doubled their rate of oxygen extraction, and had no rise in stroke volume. Judged by oxygen consumption, our patients would fall into the light exercise group of Donald's team, and it may be argued that the exercise which they did was not strenuous enough to raise the stroke volume. On the other hand, Dexter et al. (1951) found that even light effort could raise the stroke volume by as much as 20 per cent in the normal subject. More recently Wang, Marshall, and Shepherd (1960) have investigated this problem and their results are in general agreement with those of Donald. While acknowledging this possible objection, we consider that the relatively fixed stroke volume in our patients is evidence in favour of a functionally rigid right ventricle.

We have already remarked how our patients resemble those with constrictive pericarditis: this analogy can now be driven further. In constrictive pericarditis, the cardiac output and stroke 
volume are both low (Eliasch, Lagerlöf, and Werkö, 1950; Wilson et al., 1954). The stroke volume is fixed, remaining unchanged with exercise, so that any increase in cardiac output is due solely to tachycardia (Sawyer et al., 1952). These are precisely our findings in endomyocardial fibrosis. The small stroke volume reflects the obliterated cavity of the ventricle. Again, the sharp rise in right atrial pressure with effort and its subsequent slow return to the resting level is another feature common to both diseases. The square-wave response to the Valsalva manœuvre has been described in constrictive pericarditis (Gimlette, 1959) but is of course non-specific, although here again we constantly obtained this result. The same applied to the rise in right atrial pressure and the fall in peripheral arterial pulse pressure with inspiration, although in endomyocardial fibrosis this may in part be due to an increase in tricuspid regurgitation on inspiration (McMichael and Shillingford, 1957). Finally, the failure of digoxin to influence the height of the right atrial pressure in constrictive pericarditis was emphasized by McMichael (1952) and our results show that the same is true in endomyocardial fibrosis.

We were particularly interested when we found that digoxin failed to lower the right atrial pressure in endomyocardial fibrosis, for when a rise in central venous pressure is due to myocardial failure, there is a rapid fall when digoxin is given intravenously. We infer therefore that myocardial failure is not a factor promoting the high venous pressure in these patients, and this distinguishes them from patients with "cardiomyopathy" whom superficially they may occasionally resemble (personal unpublished observations).

So far we have been concerned with what may be called the circulatory adjustments that occur when the right ventricle is severely affected. It is also relevant to state again that the moderate anæmia and arterial oxygen desaturation, commonly found, burden still further the deformed hearts of our patients. Finally, therefore, we must consider the broader question of how their cardiac output is maintained and increased on exercise. It is difficult to believe that the right ventricle can be very efficient in this respect, for, as we have already shown, not only may its cavity be greatly shrunken but both its diastolic filling, and ultimately its systolic work, are inadequate. In the early stages of the disease powerful right atrial contraction may be an important factor, but when this chamber dilates, the muscle becomes thin and stretched, so that atrial systole can contribute little. Moreover, when the atrium becomes aneurysmal, atrial fibrillation commonly supervenes-a complication that has occurred in about half our cases. Abrahams (1962) believed that the atrium ultimately played no part in maintaining the circulation, and we see no reason to change this view.

There is, however, one interesting fact that emerges from studying our pressure tracings. It has been noted that the diastolic plateau/systolic peak ratio in the right ventricle may be more than 50 per cent (Table I). In two of our patients the level of the diastolic plateau pressure in the right ventricle exceeded the diastolic pressure in the pulmonary artery, while in two others these two pressures were approximately equal. In extreme examples of the disease, therefore, there may be a pressure gradient from the right ventricle to the pulmonary artery during a significant part of ventricular diastole: conditions are, therefore, favourable for blood to flow through the pulmonary valve during diastole as well as during systole, and it is theoretically possible that the cardiac output may be maintained in part by this means. Pulmonary arterial and right ventricular pressure tracings from one such patient are shown in Fig. 3 and it will be seen that the diastolic plateau pressure was $18 \mathrm{~mm}$. $\mathrm{Hg}$, while the pulmonary arterial diastolic pressure was initially 10 and rose gently to $18 \mathrm{~mm}$. $\mathrm{Hg}$. These pressures were not recorded simultaneously, but in close succession, and the results may thus be criticized. Nevertheless, we believe that such a diastolic flow to the pulmonary artery may well occur.

Abrahams (1962) suggested that the flow of blood through these hearts was kept up by the very high venous pressure, which was therefore responsible for the cardiac output. In the light of further experience there seems no satisfactory alternative explanation. Presumably the rise in output on effort is due to the rise in central venous pressure which has been found to occur, and which will push more blood through the right heart. The mechanism by which this high venous pressure is initiated and maintained is not obvious, although regional changes in venomotor tone may be 
important. We do not know what mechanisms are ultimately the most important, and much further work is necessary before these fascinating problems will be solved.

\section{SUMmaRY AND CONCLUSIONS}

The morbid anatomical features of endomyocardial fibrosis are briefly described. In relating structure to function there are three important factors, namely endocardial rigidity with impaired diastolic filling of the ventricle, incompetence of the atrio-ventricular valves, and progressive obliteration of the ventricular cavity. These have been studied in over 30 patients with severe disease of the right ventricle.

The cardiac output is low, the stroke volume is small, and there is increased blood oxygen extraction in the resting patient. The right ventricular pulse tracing shows a "dip-and-plateau" configuration, and the diastolic plateau/systolic peak ratio is commonly 50 per cent or more.

Moderate leg exercise leads to a rise in cardiac output which is mainly due to an increase in heart rate: the stroke volume tends to remain fixed. The increase in blood oxygen extraction with effort is less than in normal subjects. The right atrial pressure rises on effort, and returns very slowly to the resting level.

Intravenous digoxin has no effect on the height of the venous pressure and it is inferred that myocardial failure is not present.

The right atrial pressure rises on inspiration and falls when the patient is tilted from the horizontal to the vertical position.

The peripheral arterial pulse is of the paradoxical type, the pulse pressure diminishing on inspiration; there is a "square-wave" response to the Valsalva manœuvre with no subsequent "overshoot."

Our results have been compared with those reported in constrictive pericarditis by other workers. It is concluded that the two conditions are functionally very similar.

In some advanced examples of the disease the diastolic plateau pressure in the right ventricle may exceed the diastolic pressure in the pulmonary artery. It is thus possible that blood may flow from the right ventricle onwards in diastole as well as systole. This phenomenon, together with the very high central venous pressure, may be one of the ways in which the forward cardiac output is maintained.

The equipment used in these studies was provided from a generous grant from the Nuffield Foundation. It is a pleasure to record our gratitude, and also to thank our colleagues of the Department of Radiology, Dr. W. P. Cockshott, and Dr. C. J. Barton, for their willing co-operation. We are indebted to Mr. Frank Speed and Mr. Doig Simmonds for the photographs and illustrations.

Note: Much of the data presented in this paper forms part of a thesis for the degree of M.D. to be submitted by one of us (E.H.O.P.) to the University of Cambridge.

\section{REFERENCES}

Abrahams, D. G. (1960). The pattern of mitral valve disease in Southern Nigeria. Quart. J. Med., (n.s.), 29, 629.

- (1962). Endomyocardial fibrosis of the right ventricle. Quart. J. Med., (n.s.), 31, 1. cardial fibrosis. Evidence in favour of the existence of an azygos/pulmonary venous shunt. Clin. Sci., 24, 69.

Alajouanine, T., Castaigne, P., Lhermitte, F., and Gambier, J. (1959). Encéphalite puis endocardite fibroplastique d'origine filarienne. Rev. neurol., 101, 656.

Barratt-Boyes, B. G., and Wood, E. H. (1957). Hemodynamic response of healthy subjects to exercise in the supine position while breathing oxygen. J. appl. Physiol., 11, 129.

Bloomfield, R. A., Lauson, H. D., Cournand, A., Breed, E. S., and Richards, D. W. (1946). Recording of right heart pressures in normal subjects and in patients with chronic pulmonary disease and various types of cardiocirculatory disease. J. clin. Invest., 25, 639.

Burwell, C. S., and Robin, E. D. (1954). Some points in the diagnosis of myocardial fibrosis. Trans. Ass. Amer. Phycns, 67, 67.

Clark, G. M., Valentine, E., and Blount, S. G. (1956). Endocardial fibrosis simulating constrictive pericarditis. New Engl. J. Med., 254, 349.

Davies, J. N. P., and Ball, J. D. (1955). The pathology of endomyocardial fibrosis in Uganda. Brit. Heart J., 17, 337. 
Dexter, L., Whittenberger, J. L., Haynes, F. W., Goodale, W. T., Gorlin, R., and Sawyer, C. G. (1951). Effect of exercise on circulatory dynamics of normal individuals. J. appl. Physiol., 3, 439.

Donald, K. W., Bishop, J. M., Cumming, G., and Wade, O. L. (1955). The effect of exercise on the cardiac output and circulatory dynamics of normal subjects. Clin. Sci., 14, 37.

- - — - and Wade, O. L. (1954). A study of minute to minute changes of arterio-venous oxygen content difference, oxygen uptake and cardiac output and rate of achievement of a steady state during exercise in rheumatic heart disease. J. clin. Invest., 33, 1146.

Eliasch, H., Lagerlöf, H., and Werkö, L. (1950). Diagnos av adhesiv pericardit med sarskild hansyn till hjartkatetrisering. Nord. Med., 44, 1128.

Gerbaux, A., Ben Naceur, M., de Brux, J., and Lenègre, J. (1956). Contribution à l'étude de l'endocardite pariétale fibroplastique avec éosinophilie sanguine (Endocardite de Loëffler). Arch. Mal. Caur, 49, 689.

— Garin, J. P., and Lenègre, J. (1957). Cardiopathie et filariose. Bull. Soc. méd. Hôp. Paris, $73,873$. and Rullière, R. (1958). L'endocardite pariétale fibroplastique. Sem. Hôp. Paris, 34, 1780.

Gimlette, T. M. D. (1959). Constrictive pericarditis. Brit. Heart J., 21, 9.

Goodwin, J. F., Gordon, H., Hollman, A., and Bishop, M. B. (1961). Clinical aspects of cardiomyopathy. Brit. med. J., 1, 69.

Gunnar, R. M., Dillon, R. F., Wallyn, R. J., and Elisberg, E. I. (1955). The physiologic and clinical similarity between primary anyloid of the heart and constrictive pericarditis. Circulation, 12, 827.

Hansen, A. T., Eskildsen, P., and Götzsche, H. (1951). Pressure curves from the right auricle and the right ventricle in chronic constrictive pericarditis. Circulation, 3,881 .

Hetzel, P. S., Wood, E. H., and Burchell, H. B. (1953). Pressure pulses in the right side of the heart in a case of amyloid disease and in a case of idiopathic heart failure simulating constrictive pericarditis. Proc. Mayo Clin., 28, 107.

McKusick, V. A., and Cochran, T. H. (1952). Constrictive endocarditis. Report of a case. Bull.Johns Hopk. Hosp., 90, 90.

McMichael, J. (1952). Dynamics of heart failure. Brit. med. J., 2, 525.

- - , and Shillingford, J. P. (1957). The role of valvular incompetence in heart failure. Brit. med. J., 1, 537.

Sawyer, C. G., Burwell, C. S., Dexter, L., Eppinger, E. C., Goodale, W. T., Gorlin, R., Harken, D. E., and Haynes, F. W. (1952). Chronic constrictive pericarditis: further consideration of the pathologic physiology of the disease. Amer. Heart J., 44, 207.

Shillingford, J. P., and Somers, K. (1961). Clinical and hæmodynamic patterns in endomyocardial fibrosis. Brit. Heart J., 23, 433.

Wang, Y., Marshall, R. J., and Shepherd, J. T. (1960). The effect of changes in posture and of graded exercise on stroke volume in man. J. clin. Invest., 39, 1051 .

Yu, P. N. G., Lovejoy, F. W., Joos, H. A., Nye, R. E., and Mahoney, E. B. (1953). Right auricular and ventricular pressure patterns in constrictive pericarditis. Circulation, 7, 102.

Wilson, R. H., Hoseth, W., Sadoff, C., and Dempsey, M. E. (1954). Pathologic physiology and diagnostic significance of the pressure pulse tracings in the heart in patients with constrictive pericarditis and pericardial effusion. Amer. Heart J., 48, 671. 